\title{
Effect of synovial fluid insulin rate on mesenchymal stem cells differentiation to chondrocyte
}

\begin{abstract}
The demand for effective treatment strategies of cartilage cause to autologous MSC used for the repair of cartilage defects in patient. Tissue engineering has developed strategy for the repair and regeneration of a variety of tissues. In this study surveyed effect of some factors on MSCs differentiation to chondrocyte such as present of PCL scaffold and amount of synovial fluid. Total cellular RNA was extracted and was used for analysis by quantitative RT-PCR. Cell culture for differentiation assay performed in 6 well pellets by DMEM high glucose medium with supplement of $10 \%$ FBS and synovial fluid $5 \%$ and $10 \%$ of medium add to pellets for 21 days. The scaffold surface topography was captured by SEM electron microscope. MTT assay results in this study showed that the cells proliferation increased from 1st day to 2 st days on electro spun Nano-fibrous scaffold. Cellular attachment and proliferation of MSCs on PCL substrate, and control group in the first day to 2st days. MTT assay and Real-time PCR analysis and the expression of chondrogenic specific genes at pellet in comparison with control group demonstrated cell survival ability and proliferation. It is suggested that this method can be used for induction of chondrogenesis.
\end{abstract}

Keywords: mesenchymal stem cells, insulin, synovial fluid, differentiation, chondrogenic

\author{
Volume 3 Issue 2 - 2018
}

\begin{abstract}
Saleh Soleimani,' Habibollah Nazem,' Mohammad Fazilati ,' Mohammad Pezeshki Modarres, ${ }^{3}$ Seyed Mohammad Atyabi ${ }^{2}$

'Department of biology, Payame Noor University, Iran

${ }^{2}$ Department of pilot biotechnology, Pasteur institute of Iran, Iran

${ }^{3}$ Tissue Engineering and Regenerative Medicine Institute, Islamic Azad University, Iran
\end{abstract}

\begin{abstract}
Correspondence: Seyed Mohammad Atyabi, Department of pilot biotechnology, Pasteur institute of Iran, Tehran, Iran, Tel +989122061565, Email mohammadatyabi@yahoo.com
\end{abstract}

Received: March 29, 2018 | Published: June 13, 2018
Abbreviations: FGF, fibroblast growth factors; BMP, bone morphogenic proteins; HA, hyaluronic acid; PCL, poly e-caprolactone; SF, synovial fluid

\section{Introduction}

In recent years, Effective Clinical treatment of cartilage diseases has become more promising., especially with an increase in the number of patients with skeletal system defects. ${ }^{1}$ Hence, new therapeutic approaches have been developed to treat patients. ${ }^{2}$ HMSCs or Human Mesenchymal stem cells is found in bone marrow and other mesenchymal tissues, such as cartilage and bone. ${ }^{3}$ Recently autologous hMSC has been used for the purposes of healing and repairing patients with cartilage defects. ${ }^{4}$

Tissue engineering combines different biological fields. Such as material sciences, engineering, and surgery to supply new functional tissues by living cells, signaling molecules, and biometrics. In recent decades, these policies have been greatly developed, and several groups of researchers focus on these therapeutic Approach for Repair and reconstruction of a different tissues. ${ }^{5,6}$

Articular cartilage is one of the attractive targets for tissue engineering strategies, because it has been well proven that harm to articular cartilage, without direct access to a Specified resource of repairing cells, is not self-healing. ${ }^{7}$ Some research efforts have led to the isolation of progenitor cells and understanding chondrogenic differentiation mechanisms that exist. Protocols for the Distinction and mitotic extension of adult human bone marrow-derived hmcs and the special, culture conditions extend for their chondrogenic differentiation. ${ }^{8-10}$

Synovial fluid (SF) lubricates articular joint surfaces and nourishes the cells of articular cartilage and act as a shock absorber also contains many hormone such as growth factors like TGF $\beta-1 .{ }^{11}$ Hyaluronic acid (HA) based polymers is a principal component of SF, that it is secreted by synoviocytes, are protease inhibitors and glycoproteins. ${ }^{12}$ Poly (e-caprolactone) (PCL) is one of the convenient synthetic biomaterials, because it has many comprehensive Specification like: flexibility, biocompatibility, mechanical strength and biodegradability It also provides a suitable bio- substrate at the microenvironment level for seeding of the cell, but PCL has hydrophobic nature and this property cause to low cell loading in the initiatory step of the cell culture and its cause to less cellular adhesion, proliferation and migration. ${ }^{13}$

\section{Material and method}

In this experimental study, the hMSCs obtained from the Cell Bank of Pasteur institute of Iran. 3-[4,5-dimethylthiazol-2-yl]-2, 5 diphenyl tetrazolium bromide MTT, (Sigma) FBS (Fetal Bovine Serum, Gibco), Pen/Strep (Gibco, 100U/ml), DMEM (Dulbecco's Modified Eagle's Medium, Gibco), Trypsin/EDTA 0.025\% (Gibco,) were purchased. Synovium was obtained from the knee of arthritic patients undergoing arthroplasty from Loghman Hakim Hospital of Tehran.

Cell viability of hMSCs measured at 1and 2, days by MTT assay. The absorbance values of Formosan solutions were measured by ELIZA method at $570 \mathrm{~nm}$. The scaffold surface topography was captured by SEM electron microscope. Cell culture for differentiation assay performed in 6 well pellets by DMEM high glucose medium with supplement of $10 \%$ FBS by adding synovial fluid $5 \%$ and $10 \%$ of medium that changed twice a week at the condition of $95 \%$ air, $5 \%$ $\mathrm{CO}_{2}$ at $37^{\circ} \mathrm{C}$ for 21 days.

Total RNA extraction caried out by using the guanidine thiocyanate extraction method described by Chomczynski and Sacchi. These 
RNA preparations were used for analysis by RT-PCR. Relative quantification of mRNA expression of hyaluronan enzymes (has2 ) and collagen type II was performed. These related Primer gene showed in below Table $1 .{ }^{14} \mathrm{cDNA}$ was synthesized by using a highquality cDNA reverse transcription kit. The PCR reaction performed at $94^{\circ} \mathrm{C} 5 \mathrm{~min}$ for denaturation, and 30 cycles at $94^{\circ} \mathrm{C} 45 \mathrm{~s}, 60^{\circ} \mathrm{C} 45 \mathrm{~s}$, and $72^{\circ} \mathrm{C} 45$ sand final extension at $72^{\circ} \mathrm{C}$ for $5 \mathrm{~min} .1 .5 \%$ agarose gel electrophoresis used for PCR products $(3 \mu)$ analyzed containing safe stain, and the resulting bands were visualized by UV transillumination.

All the experiments were performed in triplicate and data analyzed by a Dunnet one way (ANOVA) by using software SPSS version 16.0 and the data reported as the mean value with the standard deviation of $\pm 0.05 .{ }^{15}$

Table I Primer sequence for has-2, collagen type II and beta-actin gene ${ }^{14}$

\begin{tabular}{ll}
\hline Gene name & Sequence \\
Has-2 & 5-CAGACAGGCTGAGGACGACTTTAT-3 \\
& 5-GGATACATAGAAACCTCTCACAATGC-3 \\
Collagen type II & 5-CCGCCGCTTCACCTACAGC-3 \\
& 5-TTTGTATTCAATCACTGTCTTGCC-3 \\
Beta-Actin & 5-GGCACCCAGCACAATGAAG-3 \\
& 5-CCGATCCACACGGAGTACTTG-3 \\
\hline
\end{tabular}

\section{Result}

Chemical and biochemical component of synovial fluid had measured by different method such as enzymatic, colorimetric and Eliza method that show in Table 2. These results show that synovial fluid as a supplementary medium contains requiring component for cell proliferation and differentiation.

Table 2 Synovial fluid chemical and biochemical component

\begin{tabular}{ll}
\hline Test & Amount \\
\hline Glucose & $41 \mathrm{mg} / \mathrm{dl}$ \\
Total protein & $4.1 \mathrm{mg} / \mathrm{dl}$ \\
Albumin & $1.7 \mathrm{mg} / \mathrm{dl}$ \\
Insulin & $100 \mu \mathrm{lu} / \mathrm{ml}$ \\
Hyaluronic acid & $2-4 \mathrm{mg} / \mathrm{ml}$ \\
\hline
\end{tabular}

HMSCs cultured for 21days on PCL scaffold at present and absent of CAP and different amount of synovial fluid carried out. MTT test for cell viability and mRNA expression for differentiation were assessed. MTT assay results in this study showed that the cells proliferation increased from 1day to 2days on electro spun nanofibrous scaffold. MTT test for different conditions of cell culture showed at Figure 1.

The image of the electron microscope from the PCL nanofibrous scaffold surface and the cellular connection to the scaffold surface is shown in Figure 2. The scaffold causes the cells seed better when they are cultured.

Cell proliferation and cellular attachment of hMSCs on PCL at the present of synovial fluid $10 \%$, Higher rate than to the synovial fluid $5 \%$, and. These results confirmed that increase in amount of synovial fluid has effect on cell proliferation, viability and differentiation due increase of insulin rate. For hMSCs, the cell proliferation gently increased on PCL nanofibrous from 1 to 2 days.

RT-PCR analyses: An expression analysis for the known chondrogenic markers has-2 and collagen type II genes using RT-PCR was performed for hMSCs differentiation. This method showed that has-2 and collagen type II were induced during the course of hMSCs differentiation into chondrogenic lineage. In present of PCL substrate and adding 5\% and 10\% synovial fluid increased collagen type II expression at days 14 and 21, when compared with the cells cultured in the control groups. The expression of Collagen type II gene in primary days was low but increase piecemeal that show in Figure 3. Has-2 gene expression is lately and expressed at days 14 and 21 that show in Figure 4.

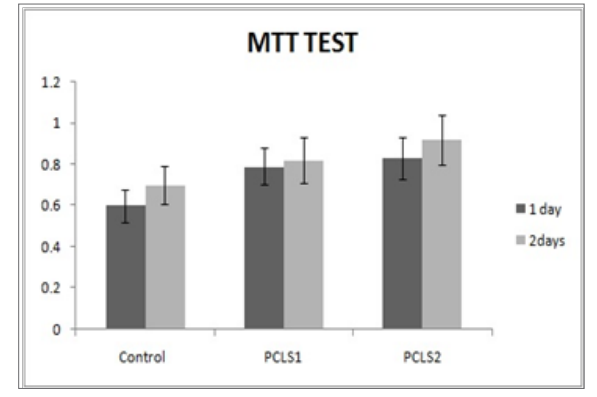

Figure I MTT test for cell proliferation at I, 2, days at different conditions PCLSI: poly caprolactone + synovial fluid $5 \%$, PCLS2: poly caprolactone + synovial fluid $10 \%$.

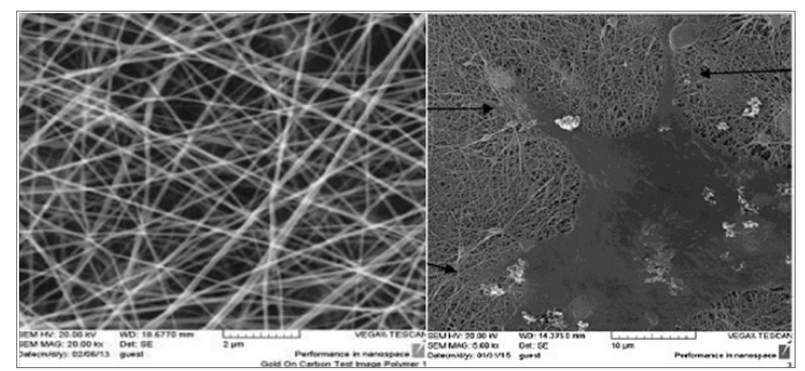

Figure 2 SEM topography of PCL nanofibrous scaffold surface and the cellular connection to the scaffold surface.

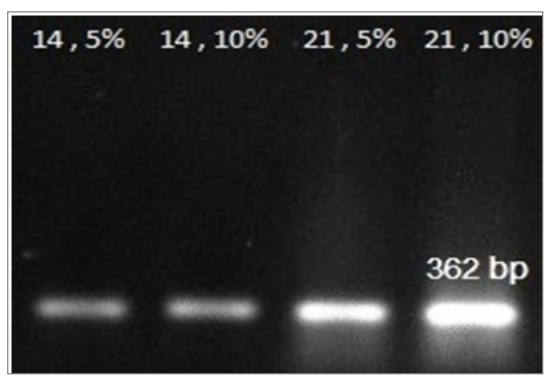

Figure 3 RT-PCR analysis results for collagen 2 gene expressions at I4, 2 I days in $5 \%$ and $10 \%$ amount of synovial fluid on PCL.

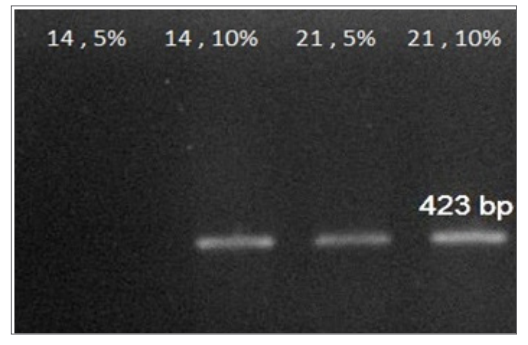

Figure 4 RT-PCR analysis results for Has-2 gene expressions at I4, 2 I days in $5 \%$ and $10 \%$ amount of synovial fluid on PCL. 


\section{Discussion}

Chondrogenesis can be made in several different ways that each of them has limitations..$^{16}$ One of the complexities of chondrogenesis is the study of a simple laboratory system. HMSCs can be differentiate into multiple connective tissues, such as cartilage, ligament, muscle, bone, fat, and tendon. ${ }^{17}$ Several scientists have presented reports of cartilage differentiation of hMSCs in a pellet micro mass culture containing bioactive substances such as TGF- $\beta$, BMP-6 and dexamethasone. ${ }^{18}$ In this study We showed that human synovial fluid of the human's knee has a potentially effective potential for chondrogenesis differentiation of hMSCs on PCL. ${ }^{19}$ The PCL scaffold as a surface for cell support provides conditions for Adhesion, growth, proliferation and differentiation of cells.

SF can acts as a sample for finding perfect combination of differentiation factors and deserves more research on its constituent parts and its potential for chondrogenesis. ${ }^{20,21}$

RT-PCR analysis result for collagen 2 and Has-2 gene expressions at 14,21 days in $5 \%$ and $10 \%$ of medium synovial fluid show that collagen 2 gene expressed increased from 14 to 21days and Has-2 gene expressed at 14 and 21 days. And $10 \%$ of synovial fluid has more effect on differentiation to chondrocyte at the present of PCL. HAS-2 is the major expressed isoform in chondrocytes and cartilage; there are appreciable levels of HAS- 1 in contrast to reports by Nishida et al. ${ }^{22}$

The results suggest the fact that SF Includes such factors as insulin and hyaluronic acid which enhance and expansion of cartilage of MSCs and progenitor cells. SF also includes the following subtypes of fibroblast Growth Factors (FGF), TGF $\beta$, and Bone Morphogenic Proteins (BMP), which are capable of creating a reciprocal and mutual differentiation. ${ }^{22}$ Although, stimulation by the SF is not enough to detect HAS-2 or type II collagen or some aggrecan on protein level, But identifiable at mRNA level. ${ }^{23-25} \mathrm{SF}$ has a great potential to persuade chondrogenic differentiation. Approximately in synovial fluid hyaluronic acid concentration is $2-4 \mathrm{mg} / \mathrm{ml}$. Prolactin hormone is one of the effective factors in the human synovium that causes proliferation and chondrogenic differentiation of hMSCs and becoming cartilage. ${ }^{26}$

SF also consist insulin in high concentration and TGF- $\beta 1$ and also contains glucose and protein that cause to cell proliferation and differentiations. ${ }^{11,15}$ High concentration of insulin cause to glucose inters to the cells and initiate anabolic pathways and cells inter to proliferation cycle and differentiations state.

\section{Conclusion}

In this study, our obtained results from MTT assay, and the expression of chondrogenic specific genes in comparison with control groups demonstrated cell survival ability, proliferation and cell differentiation by synovial fluid on PCL. It is suggested that this method can be used for induction of chondrogenesis.

\section{Acknowledgements}

None.

\section{Conflict of interest}

Author declares no conflict of interest.

\section{References}

1. Jeffcott L, Rossdale P, Freestone J, et al. An assessment of wastage in Thorough bred racing from conception to 4 years of age. Equine Vet $J$. 1982;14(3):185-198.

2. Frisbie D, Ghivizzani S, Robbins P, et al. Treatment of experimental equine osteoarthritis by in vivo delivery of the equine interleukin-1 receptor antagonist gene. Gene Ther. 2002;9(1):12-20.

3. Owen M, Friedenstein A. Stromal stem cells: marrow-derived osteogenic precursors. Ciba Found Symp. 1988;136:42-60.

4. Wakitani S, Goto T, Pineda SJ, et al. Mesenchymal cell-based repair of large, full-thickness defects of articular cartilage. J Bone Joint Surg Am. 1994;76(4):579-592.

5. Duncan DR, Breuer CK. Challenges in translating vascular tissue engineering to the pediatric clinic. Vasc Cell. 2011;3(1):23.

6. Pearson R, Bhandari R, Quirk R, et al. Recent advances in tissue engineering: an invited review. J Long Term Eff Med Implants. 2002;12(1):1-33.

7. Hunter W. Of the structure and diseases of articulating cartilages, by William Hunter, surgeon. Philosophical Transactions. 1742;42(462471):514-521.

8. Hanada K, Solchaga LA, Caplan AI, et al. BMP-2 induction and TGF$\beta 1$ modulation of rat periosteal cell chondrogenesis. $J$ Cell Biochem. 2001;81(2):284-294.

9. Haynesworth S, Goshima J, Goldberg V, et al. Characterization of cells with osteogenic potential from human marrow. Bone. 1992;13(1):81-88.

10. Johnstone B, Hering TM, Caplan AI, et al. In vitro chondrogenesis of bone marrow-derived mesenchymal progenitor cells. Exp Cell Res. 1998;238(1):265-272

11. Lynch T, Caron J, Arnoczky S, et al. Influence of exogenous hyaluronan on synthesis of hyaluronan and collagenase by equine synoviocytes. Am J Vet Res. 1998;59(7):888-892.

12. Okazaki R, Sakai A, Uezono Y, et al. Sequential changes in transforming growth factor (TGF)- $\beta 1$ concentration in synovial fluid and mRNA expression of TGF- $\beta 1$ receptors in chondrocytes after immobilization of rabbit knees. Journal of bone and mineral metabolism. 2001;19(4):228235 .

13. Salamian N, Irani S, Zandi M, et al. Cell attachment studies on electrospun nanofibrous PLGA and freeze-dried porous PLGA. Nano Bulletin. 2013;2(1):130103

14. Antonioli E, Piccinato CA, Nader HB, et al. Modulation of hyaluronan synthesis by the interaction between mesenchymal stem cells and osteoarthritic chondrocytes. Stem Cells Int. 2015;640218.

15. Seyed Mohammad A, Fereshteh S, Shiva I, et al. Cell Attachment and Viability Study of PCL Nano-fiber Modified by Cold Atmospheric Plasma. Cell Biochem Biophys. 2015;74(2):181-190.

16. Bi W, Deng JM, Zhang Z, et al. Sox9 is required for cartilage formation. Nat Genet. 1999;22(1):85-89.

17. Ikeda R, Tsukahara S, Yoshida K, et al. Gene expression changes during the chondrogenic differentiation of human mesenchymal stem cells. Journal of Biological Sciences. 2007;7(5):729-736.

18. Mahshid M, Shirin F, Shahram AN, et al. Chondrogenic differentiation of Human Bone Marrow Mesenchymal stem cells Induced by Synovial Fluid in Vitro. Stem Cell. 2012;3(3).

19. Ogueta S, Muñoz J, Obregon E, et al. Prolactin is a component of the human synovial liquid and modulates the growth and chondrogenic 
differentiation of bone marrow-derived mesenchymal stem cells. Mol Cell Endocrinol. 2002;190(1-2):51-63.

20. Raghavachari N, Lou M. Evidence for the presence of thioltransferase in the lens. Exp Eye Res. 1996;63(4):433-441.

21. Solchaga LA, Yoo JU, Lundberg M, et al. Hyaluronan-based polymers in the treatment of osteochondral defects. J Orthop Res. 2000;18(5):773780 .

22. Nishida Y, Knudson CB, Nietfeld JJ, et al. Antisense inhibition of hyaluronan synthase-2 in human articular chondrocytes inhibits proteoglycan retention and matrix assembly. J Biol Chem. 1999;274(31):21893-21899.

23. Gobezie R, Kho A, Krastins B, et al. High abundance synovial fluid proteome: distinct profiles in health and osteoarthritis. Arthritis Res Ther.

\section{7;9(2):R36.}

24. Lettesjö H, Nordström E, Ström H, et al. Synovial fluid cytokines in patients with rheumatoid arthritis or other arthritic lesions. Scand J Immunol. 1998;48(3):286-292.

25. Krüger JP, Endres M, Neumann K, et al. Chondrogenic differentiation of human subchondral progenitor cells is affected by synovial fluid from donors with osteoarthritis or rheumatoid arthritis. J Orthop Surg Res. 2012;7(1):10.

26. Hegewald AA, Ringe J, Bartel J, et al. Hyaluronic acid and autologous synovial fluid induce chondrogenic differentiation of equine mesenchymal stem cells: a preliminary study. Tissue Cell. 2004;36(6):431-438. 